\title{
CONTRIBUIÇÃO DO DESIGN NA FEIRINHA SOLIDÁRIA DA UFU: UMA EXPERIÊNCIA PARA A VALORIZAÇÃO DE PRODUTOS LOCAIS
}

\section{CONTRIBUTION OF DESIGN IN THE "FEIRINHA SOLIDÁRIA DA UFU": AN EXPERIENCE FOR THE VALORIZATION OF LOCAL PRODUCTS}

\section{Isabella Gomes De Marco (UFU); Viviane G. A. Nunes, Dra. (UFU)}

\section{Palavras Chave}

Design para a inovação social; Estratégias sustentáveis de design; Valorização do território; Agricultura familiar

\author{
Key Words \\ Design for social innovation; Design sustainable strategies; Valorization of territory; Familiar agriculture
}

\section{RESUMO}

Este trabalho refere-se a uma ação projetual orientada ao empreendimento social denominado Feirinha Solidária da UFU. Considerada como uma inovação sociocultural, a iniciativa propõe um modo de consumo para a valorização do produtor local e do trabalho artesanal. A intervenção busca fortalecer iniciativas locais, tendo o Design como ferramenta de criação de novos cenários de produtos e serviços, para que se consolidem as relações saudáveis e sustentáveis com o território e a comunidade. A pesquisa foi baseada em referenciais do Design Estratégico, Sustentabilidade bem como nos fundamentos de Inovação Social. A metodologia adotada contempla a revisão de literatura, estudos de caso, entrevistas e projetação participativa. Os resultados da pesquisa confirmam que a adoção do Design em várias áreas de estudo e práticas é viável e essencial para a inovação e sucesso dos projetos; contudo, isto demanda esforços contínuos e integrados que visem à consolidação dos novos cenários projetados.

\section{ABSTRACT}

This work refers to an action project within a social initiative named "Feirinh a Solidária da UFU". Considered as a socialcultural innovation, the experience proposes a consumption behavior to value the local producer and the craftsmanship. The intervention seeks to strengthen the local initiatives by using Design as a tool for creating new products and services scenarios, in order to consolidate the healthy and sustainable relationships between territory and community. This research was based on references of Strategic Design, Sustainability as well as Social Innovation fundations. The methodology includes literature review, case studies, interviews and participatory design. The research results confirm that adopting design in many studies and practices is feasible and essential for innovation; however, they also highlight the need of continuous and integrated efforts towards the consolidation of the new designed scenarios. 


\section{INTRODUÇÃO}

O questionamento sobre hábitos de consumo e seus impactos surge do anseio em contribuir para o começo de um novo rumo comum que conclama por mudanças. Partindo-se da análise entre produtos, de locais a globais, a base para o entendimento do problema foi a Feirinha Solidária da UFU - empreendimento que tem como foco a valorização de produtos sociobiodiversos, a produção agroecológica e o trabalho familiar na cidade de Uberlândia/MG.

No que tange a agricultura, observa-se que o método de produção convencional e o agronegócio são apenas alguns dos muitos problemas impulsionados pelo modelo capitalista. Neste caso, a influência deste sistema faz com que o campo de cultivo se assemelhe, cada vez mais, a uma fábrica. Em contraste, o estudo da produção agroecológica é definido como um resgate da conexão com a natureza, pois elimina a ideia de dominação sobre ela.

Esta diretriz de dominação - e desvalorização do que contraria o modelo econômico atual -, foi imposta gradualmente pela globalização, abrindo um leque de questionamentos ainda maior no âmbito de consumo, como, por exemplo, o da opressão ao que o território pode oferecer em função da massificação e importação de técnicas e produtos. Com isso, perde-se o valor nas relações com troca de saberes locais e formas de expressão culturais (KRUCKEN, 2009).

Segundo Manzini (2008), se considerarmos as condições atuais do planeta e a natureza catastrófica das transformações em andamento, pode-se dizer que os designers ainda têm sido parte do problema. Este estudo busca discutir uma possível contribuição do Design, no contexto local, a partir de uma percepção sistêmica, capaz de estimular uma nova postura na concepção de artefatos e serviços, de forma que a cultura projetual seja transferida para valorização do local e sustentável (KRUCKEN, 2009).

Inserido no âmbito de inovação sociocultural e sustentabilidade, este estudo é, então, uma iniciativa de se estabelecer uma ligação entre Design e as questões ambientais e culturais, entre produção/consumo e meio ambiente, de maneira equilibrada.

O objetivo principal do trabalho foi valorizar produtos locais por meio do impulsionamento do empreendimento Feirinha Solidária da UFU, que envolve um grupo de agricultores familiares - através do Design. De forma complementar, o estudo buscou: i) estudar abordagens do Design que contribuíssem para a valorização dos produtos locais; ii) analisar a Feirinha Solidária da UFU a partir de um olhar projetual; iii) identificar hipóteses de melhoria; iv) criar campanhas para divulgar e fortalecer a marca; v) identificar possíveis efeitos na implementação das ideias geradas.

\section{A FEIRINHA SOLIDÁRIA DA UFU: CONTEXTO LOCAL E MOTIVAÇÃO}

O contexto do trabalho é o município de Uberlândia, com cerca de 700 mil habitantes, situado na região do Triângulo Mineiro/MG. A Feirinha Solidária da UFU é um empreendimento social, incubado pelo CIEPS - Centro de Incubação de Empreendimentos Populares Solidários da Universidade Federal de Uberlândia/MG. A iniciativa busca fortalecer um grupo de agricultores familiares e produtores sociobiodiversos com base na Economia Popular Solidária, ou seja, uma nova alternativa de desenvolvimento para a sociedade.

O CIEPS é um espaço que visa a desenvolver conhecimentos, habilidades e atitudes que proporcionem aos trabalhadores envolvidos em Organizações Produtivas Solidárias. A intenção é de ocupar melhor os espaços do mercado, superando a exploração por "atravessadores" e melhorando a renda dos trabalhadores através da Economia Popular Solidária, que oferece alternativas capazes de amparar os desempregados por este contexto (LAVILLE; FILHO, 2004 apud BETANHO; FERNANDES, 2016).

A Feirinha Solidária da UFU, incubada desde 2015 pelo Centro, defende uma produção e estilo de vida mais sustentável, usando técnicas da agroecologia para a produção dos alimentos, como um resgate da conexão com a natureza. Na direção oposta da produção agrícola convencional, a produção agroecológica não usa insumos químicos (mas orgânicos), respeita as sazonalidades, promove questionamentos no paradigma em busca de um bem coletivo maior e estimula a visão holística do sistema, valorizando a identidade local e as raízes culturais.

A agricultura com bases ecológicas atua não só na produção mais limpa de alimentos, mas principalmente na preservação e recuperação dos recursos naturais, na mudança da relação homem-natureza, na transformação das relações sociais, na distribuição de renda, no reverso da artificialização dos espaços e urbanização territorial (BALEM, SILVEIRA, 2002).

A motivação para a pesquisa surge com o convívio com o CIEPS e com o grupo de agricultores familiares. Tal proximidade possibilitou a identificação de dificuldades e desafios enfrentados pelos empreendedores e a percepção de que estes poderiam ser superados a partir da adoção do Design como ferramenta-chave para soluções diversas, explorando suas capacidades de gestão, inovação e sustentabilidade. 
A participação como consumidor e designer também permitiu identificar problemas relacionados ao trabalho coletivo e à divulgação dos fundamentos da iniciativa. Nesse contexto, para dinamizar os recursos do território e valorizar seu patrimônio cultural imaterial, a proposta focou na ação de "reconhecer e tornar reconhecíveis" os valores e as qualidades locais. Para Krucken (2009) as contribuições do design para a valorização de produtos locais podem ser agrupadas em três linhas:

- Promover a qualidade dos produtos, do território, dos processos de fabricação;

- Apoiar a comunicação, aproximando consumidores e produtores e intensificando as relações territoriais;

- Apoiar o desenvolvimento de arranjos produtivos e cadeias de valor sustentáveis, visando ao fortalecimento de micro e pequenas empresas.

\section{MATERIAL E MÉTODOS}

Segundo Gil (2002), a presente pesquisa possui caráter exploratório pois busca novas possibilidades para um projeto já existente. Para seu desenvolvimento, foram utilizados os seguintes procedimentos:

- Revisão de literatura sobre: Design de Serviços (processos do evento da Feirinha); Design Estratégico e Sustentabilidade (potencialização do negócio de forma sustentável); e Design Gráfico (criação de identidade dos espaços e elementos comerciais);

- Coleta de dados por meio de: i) questionários físicos, com participantes internos do empreendimento (Feirinha Solidária da UFU), produtores e membros do CIEPS (coordenadores e bolsistas); ii) questionário online (público livre).

Os questionários buscaram entender o público alvo, identificar questões sobre compra de verduras, frutas e folhas em geral, interesses em temas como sustentabilidade, inovação social, consumo consciente, saúde, economia popular solidária.

\section{A INTERVENÇÃO PROPOSTA BASEADA NO REFERENCIAL TEÓRICO ADOTADO}

Conforme mencionado, a pesquisa baseou-se em referências do Design Estratégico e de Serviços. Os princípios do Design Gráfico e de Marketing também foram utilizados na elaboração das propostas para o fortalecimento da marca e criação de nova identidade visual para o empreendimento.

\subsection{Design Estratégico como visão sistêmi- ca do contexto}

Partindo-se do princípio do estratégico do design, que é o desenvolver uma visão sistêmica sobre um determinado contexto, o primeiro aspecto analisado para o problema foi o como integrar produtos, serviços e interfaces de comunicação de forma a gerar uma coerência entre todos os elementos integrantes do empreendimento Feirinha Solidária da UFU, valorizando a iniciativa em busca de sua consolidação. A ferramenta de análise estratégica (matriz SWOT) foi utilizada para interpretar o cenário existente, buscando alternativas para superar as dificuldades (fig. 1).

Figura 1: Análise SWOT

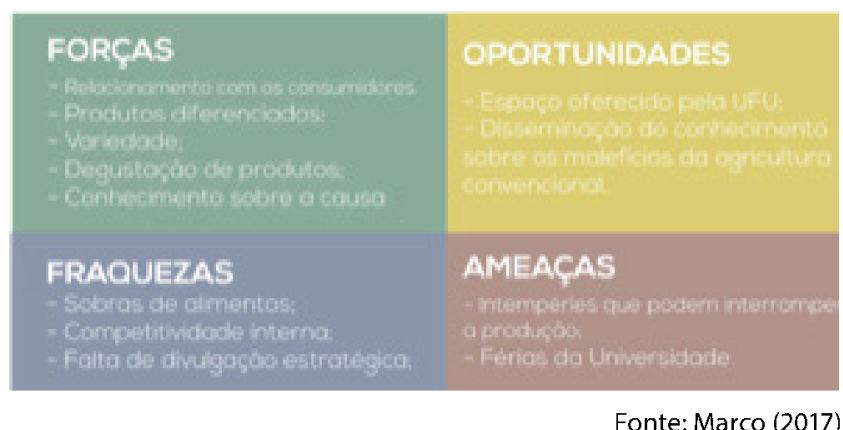

No projeto em questão, a estratégia proposta foi a integração de todos os fatores considerados relevantes na valorização da Feirinha Solidária da UFU, tais como: i) comunicação; ii) identidade; iii) sistemas de produção e iv) sistemas de consumo. Tal proposta baseia-se no pensamento de Levitt (1990 apud KRUCKEN, 2009) que evidencia que, para posicionar um produto de forma competitiva, é necessário diferenciar os serviços a ele associados e fortalecer a imagem de seu fabricante.

A ideia a ser explorada para a prática deste levantamento é da diminuição da opacidade do sistema através da comunicação do conteúdo socioambiental dos produtos e serviços da Feirinha, promovendo soluções sustentáveis. Este conceito, aliado aos problemas identificados, contribui para a definição das seguintes estratégias para alcançar os objetivos propostos pela pesquisa:

- Divulgar o empreendimento de forma mais suave e sensorial, sendo coerente com a causa da agroecologia e oferecendo uma nova maneira de enxergar a Feirinha e a Economia Popular Solidária de forma física e duradoura;

- Transformar o espaço de venda em uma convivência: Propor uma forma de venda que sugira maior envolvimento e valorize os nutrientes dos produtos agroecológicos, como um preparo de refeições cruas nos locais; 
- Incentivar o uso de kits duráveis para as refeições e compras de produtos, evitando os descartáveis.

\subsection{O papel do Design de Serviços}

Para Morelli (2009), o Design de Serviços visa à criação de novas formas de co-produção de valor, transformando empresas em organizações para a criação de valor e usuários em co-criadores ativos. No contexto do design de serviços, destacam-se três premissas básicas: i) serviços são intangíveis; ii) serviços são baseados na ligação direta entre consumidor e fornecedor; iii) consumidores podem participar da construção do serviço através da expressão de suas ideias e necessidades, consideradas pelos gestores do serviço e adaptadas à realidade do espaço (EIGLIER, 1977 apud MORELLI, 2009).

Nota-se, então que, na intangibilidade (i) não existe serviço sem consumidor: a produção e o consumo são simultâneos. Em (ii), destaca-se a importância da conexão e interação entre os atuantes - provedores do serviço e consumidores. A premissa (iii) foca na maleabilidade do serviço, que deve se adequar às ideias e necessidades que a co-criação define em seu processo (MORELLI, 2009).

Com base em Arruda (2012), são apresentadas a seguir ações para diagnosticar e propor novos cenários, ou seja, elementos de análise para projetar os serviços da Feirinha Solidária da UFU:

MAPEAR: ou seja, reconhecer o contexto da ação. $\mathrm{Na}$ pesquisa: produtores familiares que seguem técnicas agroecológicas para a produção e preceitos da Economia Popular Solidária; métodos de divulgação pouco eficientes e falta de padronização do serviço, gerando uma desvalorização do mesmo;

ENTENDER: ou seja, entender os clientes, o contexto

Figura 4: Identidade visual do empreendimento solidário

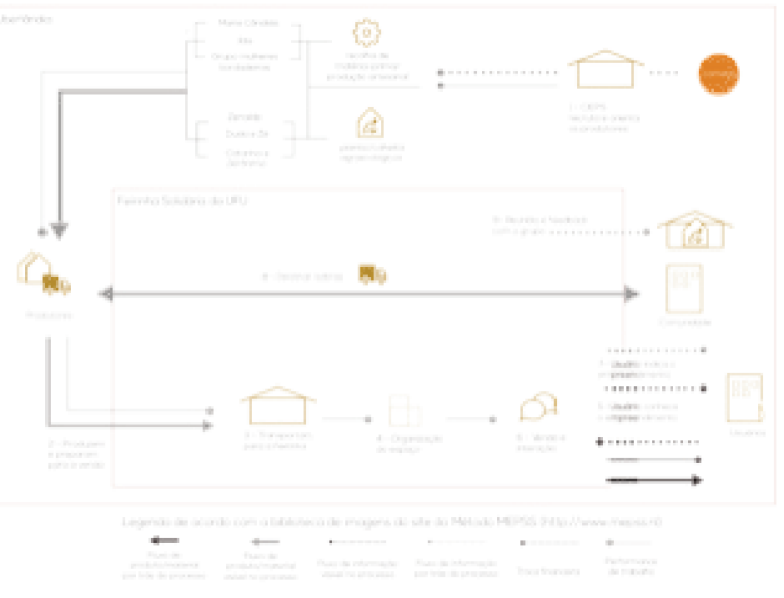

Fonte: Marco (2017) em que está inserido, seu comportamento, desejos, necessidades e problemas cotidianos. Na pesquisa: a análise dos questionários identificou que:

- $67 \%$ dos entrevistados prefere escolher os produtos pessoalmente, tendo contato com quem produziu seu alimento;

- $44 \%$ dos entrevistados que não conhece a Feirinha prefere comprar hortaliças nos Sacolões da cidade;

- apesar de saber o que é um produto agroecológico, $44 \%$ dos entrevistados não os consome sempre por falta de oportunidade;

- 50\% dos entrevistados conheceu a Feirinha por indicação;

- $57 \%$ dos entrevistados sente vontade de saber a origem e o processo do alimento que ele consome;

CONCEITUAR: ou seja, criar um conceito de serviço, sua relação de troca de valor com o cliente, objetivos, características determinantes de sua jornada e pontos de contato; Na pesquisa: esta ação está associada aos seguintes conceitos:

- Rever papel do designer - da criação de produtos para geração de experiências impactantes para as pessoas e para o planeta;

- Projetar com afetividade;

- Apoiar a mudança de paradigma (do consumo inconsciente ao crítico e solidário);

- Co-projetar;

DESENHAR: ou seja, projetar a lógica de operação do serviço, os atores, as competências técnicas e comportamentais. Na pesquisa, utilizou-se o método MEPSS e a ferramenta denominada System Map (mapa do sistema) para visualizar a lógica do serviço proposto (fig. 2).

REFINAR: ou seja, prototipar a lógica de operação do serviço, detalhar a estrutura de processos de operação de serviços e identificar os recursos disponíveis e necessários para a implantação do serviço. Na pesquisa: esta etapa será apresentada na sessão de resultados do projeto.

IMPLANTAR: ou seja, criar a visão do modelo de negócio a ser implantado, definir sua estratégia de comunicação e desenvolver o serviço.

Assim, nota-se que a prática de projetar serviços conta com pesquisas empáticas, desenvolvimento de ideias colaborativas e experimentações através de abordagens específicas.

\subsection{Design Thinking como abordagem metodológica de serviços}

Segundo Brown (2010), o Design Thinking é uma abordagem que se posiciona entre a criatividade e o 
pragmatismo, ou seja, é uma união do modelo intuitivo e de inspiração com o universo da racionalidade no processo de criação. Para Vianna et al. (2011), o tema surge da busca por novos caminhos para a inovação, e foca no ser humano que vê na multidisciplinaridade, colaboração e tangibilização de pensamentos e processos, caminhos que levam a soluções inovadoras para negócios. Seus pilares, que auxiliam no processo de criação, são a empatia, a experimentação e a colaboração.

O processo exploratório do design thinking possui três fases: i) Inspiração ou imersão: problema ou a oportunidade que motiva a busca por soluções; ii) Idealização ou ideação: processo de gerar, desenvolver e testar ideias; e iii) Implementação ou prototipagem: caminho do design ao mercado (BROWN, 2010). Baseada nestes aspectos, a pesquisa atuou conforme se segue:

Na fase se IMERSÃO - a análise dos questionários e a observação empírica possibilitou a identificação dos seguintes problemas:

- Assiduidade: Clientes não voltavam;

- Sobras de alimentos, gerando desperdício e desânimo nos produtores;

- Conflito na precificação e padronização dos produtos;

- Falta de divulgação da iniciativa e dos benefícios do produto;

- Falta de visão do consumo como ato político por parte da sociedade;

- Divulgação incoerente com o propósito sustentável da Feirinha (panfletos)

- Falta de identificação de segmentos na venda;

- Na fase de IDEAÇÃO - foram criadas hipóteses de meIhoria dos problemas levantados na fase de análise do espaço:

- transformar a Feirinha em um evento mais interessante, atraente e produtivo, poderia aumentar a assiduidade e ampliação dos clientes;

- divulgar o método de cultivo dos produtos vendidos (agroecológico) e seus benefícios poderia transformar ideias engessadas tradicionais, valorizar o produto local e demonstrar que o consumidor é parte fundamental na mudança de paradigma rumo a uma sociedade mais saudável;

- propor sistemas de compras mais elaborados facilitaria a jornada dos envolvidos, podendo evitar sobras de mercadorias. A iniciativa poderia ainda ampliar o público da Feirinha por resultar em uma nova forma de consumo dos produtos e do conceito.

Na fase de IMPLEMENTAÇÃO (que não ocorreu, efetivamente), foram esboçadas propostas de campanhas (apresentadas nos resultados deste artigo):

- Campanha de interação maior entre o produtor e consumidor, valorizando o relacionamento direto e também a qualidade e sustentabilidade do produto.

- Campanha de divulgação do estabelecimento de forma mais próxima ao receptor da mensagem, de forma e local estratégicos;

\subsection{Design Gráfico como instrumento de identidade e valor de marca}

O design gráfico é considerado peça-chave para a criação de significado sobre o símbolo visual e para gerar identificação dos consumidores com a marca, a partir de sua interpretação. Para Cruz e Maffezzolli (2011), em geral, os consumidores buscam produtos e marcas compatíveis com a sua identidade pessoal e social. Dessa forma, a imagem transmitida pelos produtos e marcas depende não apenas da oferta do fornecedor, mas, sobretudo, da percepção do usuário.

Partindo desse princípio, a pesquisa investigou os recursos gráficos necessários para promover esta identificação com o público alvo, formado por pessoas conscientes e questionadoras.

O objetivo principal, desde a oferta do serviço até a definição da nova identidade visual (figs 3 e 4), foi o de sensibilizar o público, fazendo com que se sentissem parte da mudança de paradigma e contribuindo para os processos de divulgação da iniciativa.

O logo proposto segue as ideias tidas na dinâmica, tendo em foco os seguintes aspectos físicos e representativos:

- O abraço: remete a responsabilidade, segurança, tranquilidade e confiança;

- O coração: mostra a solidariedade, a gratidão, o amor e a esperança;

Figura 3: Logo atual da Feirinha Solidária da UFU

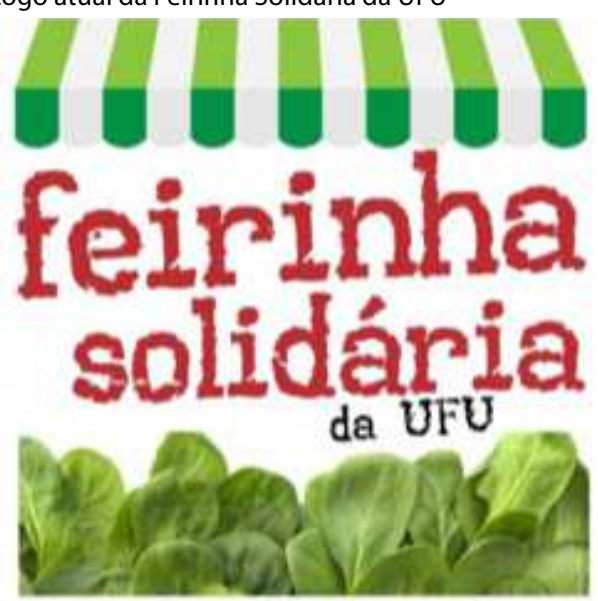

Fonte: Marco (2017) 
- A união dos ícones: representa integração, empatia, colaboração, sustentabilidade e tranquilidade no apoio;

- A folha: faz menção à sustentabilidade, à saúde e à natureza.

- Como resultado da sinergia entre os atores do sistema e o processo de criação da identidade, foram levantadas algumas hipóteses:

- Fortalecimento da imagem do território e de seus produtos e empreendimento;

- Desenvolvimento de uma cultura de co-criação no espaço da Feirinha, uma vez que a colaboração é um dos preceitos da Economia Popular solidária;

- Estímulo aos processos colaborativos de inovação e aperfeiçoamento do design local, promovendo o diálogo entre tradição e inovação e fortalecendo o sentido de pertencimento da comunidade (KRUCKEN, 2009).

\section{PROPOSTAS DE DESIGN PARA A} CONSOLIDAÇÃO DA FEIRINHA SOLIDÁRIA, A PARTIR DA VALORIZAÇÃO DOS PRODUTOS LOCAIS

Com base em toda a pesquisa desenvolvida, foram identificados campos de ação e estratégias de Design para valorizar os produtos locais, contribuindo para a con-

- a criação da identidade visual do empreendimento solidário (fig. 4);

- a criação de campanhas de divulgação em diversas mídias;

- a criação de uma exposição que incentivasse a

Figura 4: Identidade visual do empreendimento solidário

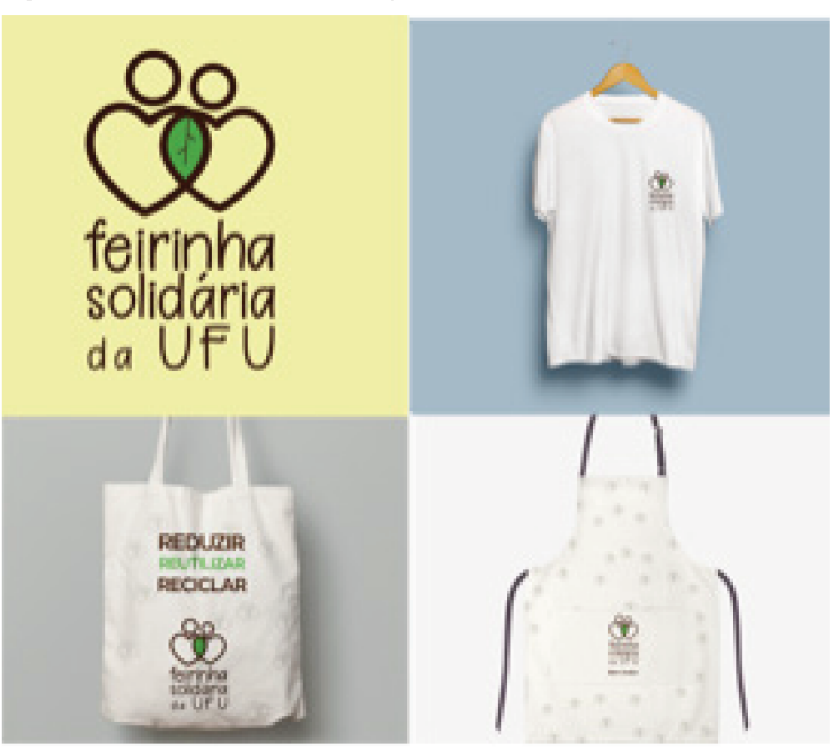

Fonte: Marco (2017)

conscientização dos visitantes, convidando-os para conhecer a Feirinha;

- atividades interativas no espaço da feira, para maior participação do público-alvo;

- a criação de um calendário anual para o destaque de datas e atividades importantes promovidas pelo empreendimento e

- a realização de um vídeo para a divulgação das famílias de pequenos agricultores apresentando suas raízes e culturas, tanto produtivas quanto de constituição como grupo social. Tais propostas serão apresentadas a seguir.

A visão sistêmica, obtida a partir dos fundamentos do design estratégico e do entendimento das relações entre produtos e serviços ofertados pela Feirinha, foi de fundamental importância para a definição das ações mencionadas (fig. 5). Assim, a partir da criação da identidade da Feirinha Solidária, foram selecionadas as melhores estratégias de comunicação para criar campanhas orientadas ao consumo responsável.

Figura 5: Visão sistêmica do projeto.

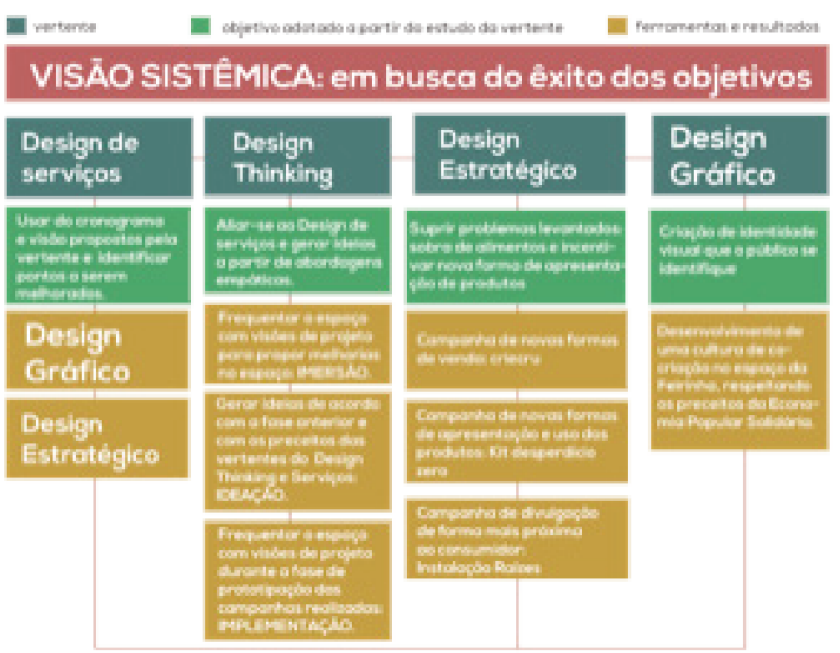

Fonte: Marco (2017)

O esquema indicado na figura 6 apresenta a construção de um ciclo fechado de ações, criado a partir da contribuição do design no empreendimento. A rede é composta por diferentes atores, na qual a compra financia a continuidade da produção, tendo o seu funcionamento a partir da comunicação do valor do empreendimento, incluindo estratégias de divulgação dos eventos.

A partir da criação da identidade para a Feirinha Solidária, serão selecionadas as melhores estratégias de comunicação de modo a criar campanhas de comunicação para o consumo responsável, que possa estimular 
Figura 6: Ciclo do projeto e seus efeitos.

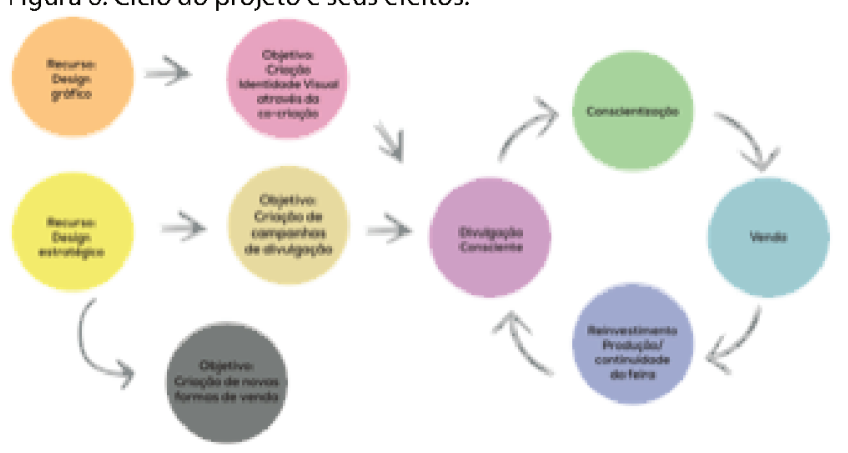

Fonte: Marco (2017)

as vendas e consolidar a Feirinha. Acredita-se que o aumento das vendas possa contribuir diretamente para o reinvestimento na produção, incrementando as soluções e estruturas adotadas pelo grupo e ampliando o alcance dos produtos.

\subsection{A criação de campanhas de divulgação em mídias diversas}

Uma das estratégias adotadas pelo projeto foi a idealização de uma campanha institucional na modalidade "exposição-instalação" denominada Raízes, para divulgar melhor o empreendimento Ferinha Solidária, seus princípios, produtos e serviços, como um todo (fig. 7). Segundo o SEBRAE (2013), este tipo de campanha caracteriza-se por conceituar, fixar sua imagem, informar seu segmento de atuação, objetivando o estabelecimento de reconhecimento de sua marca.

Como pode ser observado nas figuras 7 e 8 , a proposta considerou relevante estabelecer relações diretas entre

Figura 7: Cartaz desenvolvido para a divulgação

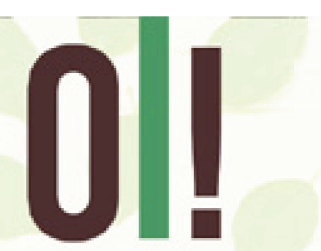

CHEGARATÉ ACU MOSTRA OUE VOCE

TEM INTERESSE EM DESENRAIZAR

HABTOS WPENGDOS.

OUF TAL DOMECARPEIDFADI?

AQUL, ACS SÁBADOS E ESPOODE

- SOLIDARIEDADE -

FEIRINHA SOLDARIA DA UFU:

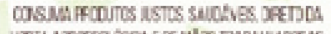

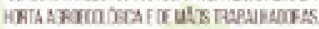

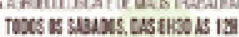

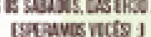

a exposição e a feirinha. A criação da faixa verde no piso visou, assim, definir um percurso para o visitante da exposição, de modo a convidá-lo a visitar também a feira. $O$ cartaz posicionado próximo ao local onde ocorre a feira foi criado para ser o ponto final do percurso e incluiu dizeres destacando a importância da iniciativa, incentivando o visitante às novas descobertas.

O objetivo da instalação RAÍZES foi de despertar o público para questões sobre responsabilidade social e consumo crítico, associando-o com as práticas da Feirinha Solidária da UFU. O nome escolhido buscou explicitar origens, questionar escolhas provindas de hábitos intrínsecos na cultura paradigmática e evidenciar a importância de refletir sobre nossas escolhas, sempre pensando em suas consequências e interpretações. O espaço contará com painéis e mesas que convidam o espectador a entender o contexto, e será finalizado com um vídeo da realidade dos produtores da Feirinha, feito pela autora para exato fim.

O local escolhido para a montagem da intervenção de divulgação foi o saguão da biblioteca da Universidade Federal de Uberlândia, por sua proximidade com espaço da Feirinha Solidária da UFU. Apesar de ser um espaço público, esta proposta visa, primeiramente, envolver os estudantes e funcionários da Universidade, a fim de mostrar o fácil alcance de uma solução no que tange à adoção de hábitos sustentáveis e solidários. Nesse sentido a seleção do espaço foi estratégica e conceitual.

Para evidenciar esta relação entre o objeto a ser divulgado e a própria divulgação, foi proposta uma linha verde no piso do percurso, chamando a atenção dos espectadores antes mesmo de conhecerem o propósito e simulando a ideia de uma raiz, que nasce no painel de apresentação da instalação.

A CrieCru (fig. 10) foi outra campanha proposta no âmbito da pesquisa para estimular novas formas de venda,

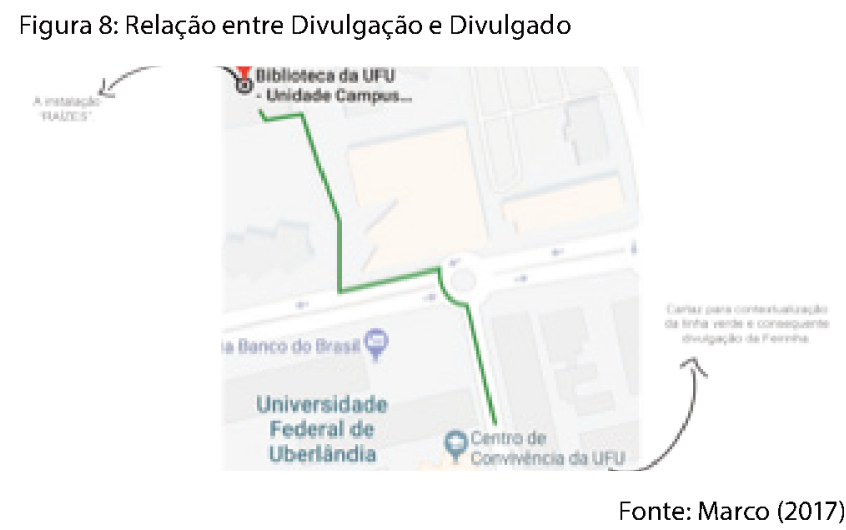


Figura 10: Proposta de divulgação da campanha "CRIECRU"

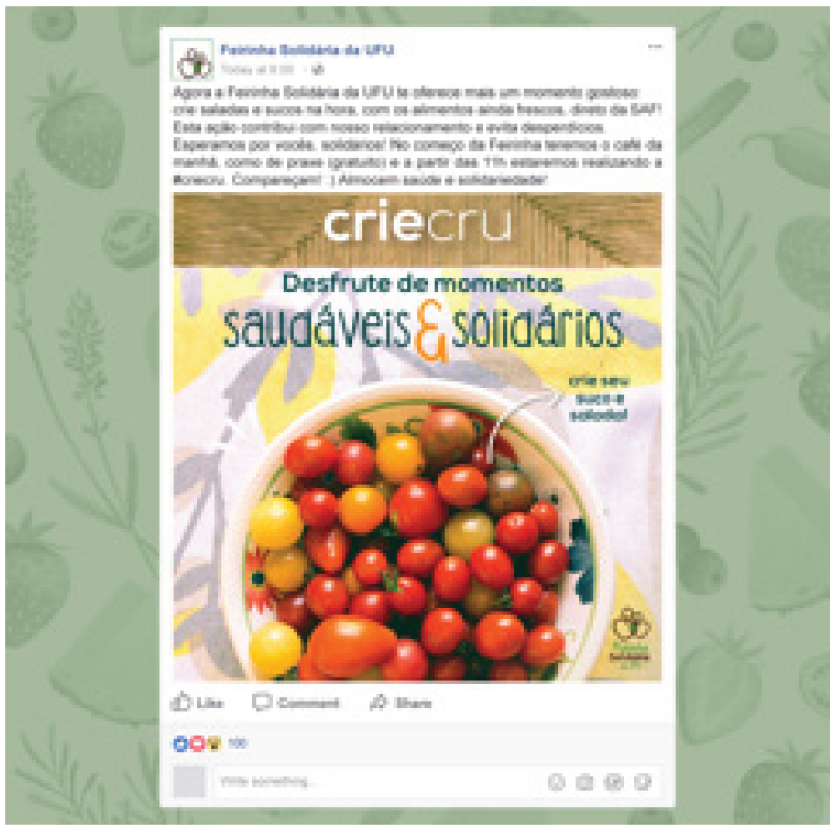

Fonte: Marco (2017)

ampliando o público consumidor e reduzir o desperdício de alimentos não vendidos na Feirinha. Baseado nas análises do questionário, de hábitos alimentares dos entrevistados, e do uso de alimentos crus para preparo de saladas e sucos, a CrieCru visou estimular o preparo de pratos frescos na própria Feira.

A iniciativa poderia contribuir para aumentar a interação e o convívio entre produtores. A proposta previa também a venda de um "kit desperdício zero", além de incentivar o uso de talheres e copos levados pelo próprio usuário. O preço do serviço seria calculado pelo próprio produtor, com base em seus conhecimentos sobre precificação obtidos nos cursos do CIEPS.

Para atingir objetivos propostos e sensibilizar o público-alvo por meio de um programa de ações comunicativas, torna-se necessário avaliar as diversas oportunidades no decorrer do ano entre datas sazonais ou situações imprevistas. Para tal fim, foram idealizados eventos baseados em datas comemorativas mensais que poderiam favorecer o consumo responsável e a valorização de produtos do território.

A proposta do calendário (fig. 11) é funcionar como "cartão fidelidade", e sua respectiva divulgação (a ser feita nas redes sociais), referente a cada mês.

Foram ainda esboçadas propostas de divulgação para as atividades a serem desenvolvidas dentro do calendário promocional, com o objetivo de dinamizar a Feirinha Solidária (fig. 12).
Figura 11: Calendário promocional de janeiro a março

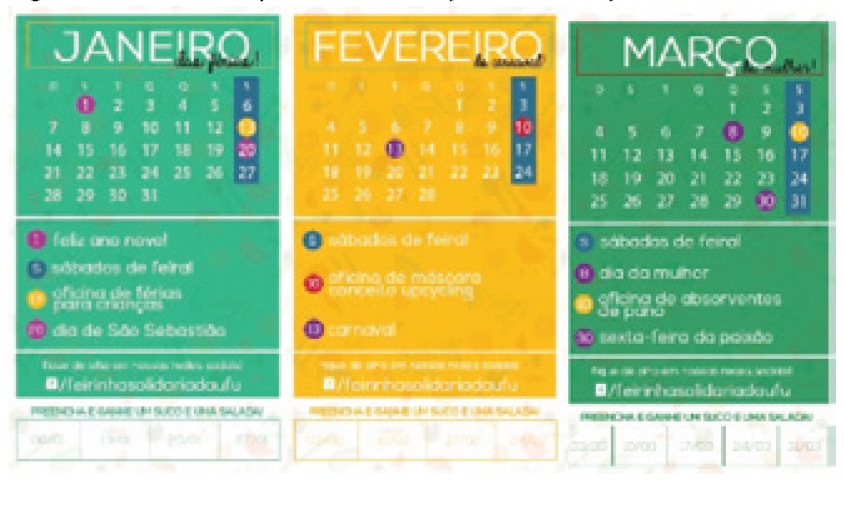

Fonte: Marco (2017)

Figura 12: Proposya de divulgação das atividades

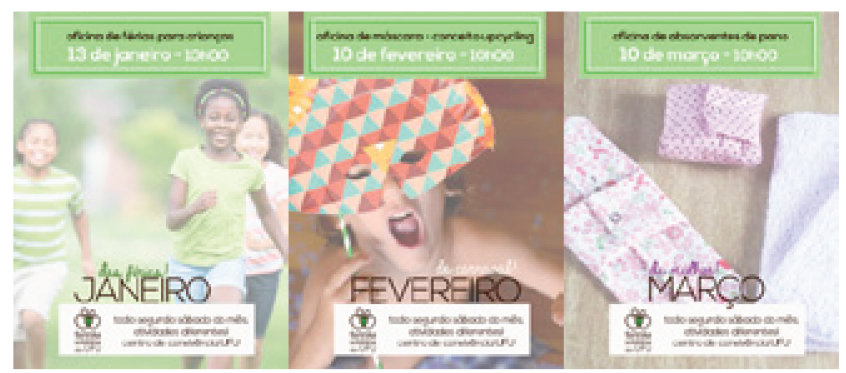

Fonte: Marco (2017)

\section{CONCLUSÕES}

Os estudos desenvolvidos durante um ano de pesquisa demonstram que a experimentação de novas possibilidades, ou seja, a redefinição da rede de atores envolvidos no sistema existente bem como a divulgação mais eficiente da Feirinha Solidária da UFU, pode resultar em efeitos positivos importantes não somente para o grupo de agricultores familiares diretamente envolvidos, mas também para toda a comunidade.

Dentre os possiveis resultados identificados como positivos pelo estudo, destacam-se: o fortalecimento das relações entre produtor-consumidor, como propõe a Economia Solidária; o aumento da venda dos produtos agroecológicos e a consequente autonomia do empreendimento e grupo de agricultores familiares; e a diminuição de desperdícios durante as vendas diretas, ocorridas no período de realização da feira.

Os achados confirmam que a adoção do Design em diferentes áreas de estudo e práticas são essenciais para a inovação e o sucesso dos projetos. Especialmente em contextos que incluem as práticas sustentáveis e a oferta de produtos e serviços, o envolvimento do e com o público-alvo torna-se essencial.

No entanto, para que experiências semelhantes à relatada nesse trabalho sejam efetivamente bem-sucedidas, 
são necessários esforços contínuos e integrados, bem como o acompanhamento de sua implementação, para que as proposições sejam avaliadas e readequadas, se necessário, no decorrer do processo, em busca da consolidação dos novos cenários projetados.

Nesse sentido, e visando ao fortalecimento do estudo e à sua concretização, na prática, os autores estão trabalhando para viabilizar um Projeto de Extensão que permita a continuidade das ideias desenvolvidas e o atendimento integral dos objetivos pretendidos, em parceria com o CIEPS e os agricultores familiares locais.

Nos dias atuais, a extensão universitária deve estar cada vez mais próxima à sociedade, configurando-se como espaço privilegiado de produção do conhecimento para a superação das desigualdades sociais existentes. Assim, espera-se que a execução do projeto de extensão mencionado contribua não somente para fortalecer o empreendimento Feirinha Solidária a partir das ações aqui apresentadas, devidamente validadas e/ou aprimoradas a partir da participação do grupo: agricultores familiares, pesquisadores e comunidade mas contribua, especialmente, para estimular novas iniciativas extensionistas de teor semelhante, aproximando a prática profissional da realidade, tão carente de soluções concretas para superar os desequilíbrios da sociedade contemporânea.

\section{REFERÊNCIAS}

KRUCKEN, L.; Design e território: Valorização de identidades e produtos locais. São Paulo: Studio Nobel, 2009.

MANZINI, E; Design para a inovação social e sustentabilidade: Comunidades criativas, organizações colaborativas e novas redes projetuais. E-papers Serviços Editoriais, Rio de Janeiro, 2008.

BETANHO, C; FERNANDES, E. Documento de descrição Feirinha Solidária da UFU. CIEPS. 2016.

BALEM, A. T; SILVEIRA, R. P; Agroecologia: Além de uma Ciência, um Modo de Vida e uma Política Pública. Santa Maria: UFSM. 2002.

GIL, A. C. Como elaborar um projeto de pesquisa. 9a reimpr. São Paulo: Atlas, 2002.

MORELLI, N. Service as Value co-production:reframing the service design process, 2009.
ARRUDA, F. Introdução ao Design de Serviços. SlideShare. Disponível em <https://pt.slideshare.net/ fazevedogomes/design-servios-2012-rev1>. Acesso em Maio de 2017. 2012.

VALEN, V. C; VEZZOLI, C; WIMMER, R. Methodology for Product Service System Innovation: How to develop clean, clever and competitive strategies in companies. Editor: Koninklijke Van Gorcum. 2005

MARCO, I. G. Contribuição do Design na Feirinha Solidária da UFU: Uma experiência para a valorização de produtos locais. Trabalho de Conclusão de Curso de graduação em Design apresentado à Faculdade de Arquitetura, Urbanismo e Design da Universidade Federal de Uberlândia. Orientador: Profa. Dra. Viviane G. A. Nunes. 2017.

BROWN, T. Design Thinking: uma metodologia poderosa para decretar o fim das velhas ideias. Rio de Janeiro: Campus, 2010.

VIANNA, M; VIANNA, Y; ADLER, K. I.; LUCENA, B; RUSSO, $B$. Design Thinking: Inovação em negócios. Rio de Janeiro: MJV Press, 2012

MAFFEZZOLLI, F.C.E; DA CRUZ, C.V. O papel dos elementos do Design Gráfico no processo de identificação com a marca. Programa de Apoio à Iniciação Científica - PAIC 2010-2011. p.597-614

SEBRAE. Como elaborar campanhas promocionais, 2013. 